CARADDE: Jurnal Pengabdian Kepada Masyarakat
$\begin{gathered}\text { https://journal.ilininstitute.com/index.php/caradde } \\ \text { Volume 2 I Nomor 1 I Agustus I2019 } \\ \text { e-ISSN: 2621-7910 dan p-ISSN: 2621-7961 }\end{gathered}$

\title{
Pelatihan Bioentrepreneurship melalui Pembuatan Kokedama di Panti Asuhan Anak Luar Biasa Asih Madiun
}

\author{
Novanda Eka Saputra ${ }^{1}$, Hendrika Betani Hernanda ${ }^{2}$, Nurhuda $^{3}$, Firman Nur Ridwan ${ }^{4}$, \\ Muhammad Waskito Ardhi ${ }^{5}$
}

\begin{tabular}{ll}
\hline Keywords: & Abstrak. Tujuan program pengabdian masyarakat ini antara \\
Kokedama; & lain melatih pengurus panti dan anak disabilitas untuk \\
Bioentrepreneurship; & mandiri secara ekonomi dengan melalui kokedama. \\
Inklusi; & Keberlanjutan program Panti Asuhan Luar Biasa Asih dalam \\
Disabilitas; & mengembangkan kokedama dan mewujudkan \\
& bioentrepreneurship secara mandiri. Terjalin hubungan \\
Corespondensi Author & sinergis antara tim pengabdian, panti asuhan, masyarakat \\
1,2,5Pendidikan Biologi, & dalam mengembangkan produk kokedama. Metode \\
3Pendidikan Akuntasi, & pelaksanaan yang dilakukan dalam kegiatan ini adalah: (1) \\
${ }^{4}$ Bimbingan dan Konseling, & sosialisasi program (2) pelatihan pembuatan kokedama sesuai \\
Universitas PGRI Madiun & dengan jenis ketunaan secara inklusi (3) pemasaran produk di \\
J1. Setia Budi No. 85 Kota Madiun & Car free day Madiun dan pemasaran melalui media sosial. \\
Email: novandaeka9@gmail.com & Hasil dari kegiatan yaitu Panti Asuhan Luar Biasa Asih \\
& terampil dalam pembuatan kokedama meskipun dengan \\
History Artikel & keterbatasan fisikataumentalyang dimiliki. Produkkokedama \\
Received: Juni-2019; & cocok diterapkan untuk bioentreprenurship karena cara \\
Reviewed: Juli -2019 & pembuatan mudah dan memanfaatkan limbah menjadi \\
Accepted: Agustus-2019 & produk bernilai jual. \\
Published: Agustus-2019 &
\end{tabular}

\section{PENDAHULUAN}

Salah satu problematika anak disabilitas adalah ketersediaan lapangan pekerjaan. Ketersediaan lapangan pekerjaan untuk disabilitas masih sangat minim. Meskipun UU tentang kesempatan kerja bagi disabilitas sudah diatur dalam UU no 8 tahun 2016 yaitu Pegawai negeri disabilitas mendapatkan jatah $2 \%$ dan $1 \%$ untuk swasta dari total pegaria.

Aksesbilitas bagi disabilitas untuk kesempatan bekerja telah terbuka luas, hal tersebut tidak serta merta mampu terimplementasikan dengan optimal di dunia kerja (Aji, 2017). Keterbatasan fisik yang dimiliki yang dimiliki anak disabilitas membuat masyarakat dan pengusaha menilai para penyandang disabilitas negatif. Menurut Prakosa (2005) masa depan penyandang disabilitas juga menjadi masalah keluarga. Ketidakmampuan sosial dan ekonomi biasanya bersifat parsial.

Sejauh ini dalam paradigma masyarakat pada disabilitas seringkali diibaratkan ketidakmampuan seseorang secara medis, sehingga disabilitas sering dianggap sebagai orang yang sakit, selalu membutuhkan pertolongan dan tidak mampu bekerja seperti manusia pada umumnya (Hamidi, 2016).

Panti Asuhan Luar Biasa Anak Asih merupakan salah satu panti di Kabupaten Madiun, Jawa Timur. Panti Asuhan ini mewadahi anak-anak dengan keterbasan diri secara fisik/mental atau istilah saat ini dikenal dengan disabilitas. Jenis ketunaan yang berada 
di Panti Asuhan Luar Biasa Asih antara lain tuna netra (keterbatasan dalam penglihatan), tuna rungu (keterbatasan dalam pendengaran), tuna grahita (keterbatasan mental) dan tuna ganda (lebih dari satu jenis keterbatasan).

Panti Asuhan Luar Biasa Asih belum mandiri secara ekonomi dengan memberdayakan atau memanfaatkan potensi yang ada di dalam Panti Asuhan. Salah satu potensi yang ada pada panti asuhan ini yaitu

Mengasah keterampilan. Disabilitas memerlukan berbagai ketrampilan (lifeskill) untuk melatih kemadirian yang dapat dijadikan sebagai sumber kehidupan kelak setelah menyelesaikan pendidikan. Kesempatan anak panti dan pengasuh untuk mengembangkan keterampilan untuk menghasilkan profit dari bahan alam (bioentrepreneurship).

Menurut Megahati (2019) keterampilan dalam bidang Biologi merupakan keterampilan yang memanfaatkan ilmu Biologi dalam menghasilkan produk-produk Biologi. Bioentrepreneurship untuk panti asuhan luar biasa sangatlah perlu untuk menunjang kemandirian. Kemandirian diharapkan dapat mendukung keberadaan anak disabilitas di masyarakat pada masa datang dan usaha pengasuh untuk mengajarkan kemandirian. Bioentrepreneurship dapat dilatih melalui pembuatan kokedama.

Pengertian kokedama secara terminologi, berasal dari kata "koke" yang berarti lumut atau moss dan "dama" yang berarti bola atau ball, sehingga kokedama biasa disebut bola lumut, Arti yang lebih luas yaitu tanah yang dibentuk seperti bola dan dibungkus dengan lumut atau sabut kelapa (Thomson, 2016). Menurut Garneti (2017) Tanaman hias untuk kokedama yang biasa menjadi pilihan adalah sukulen dan kaktus.

Pelatihan bioentrepreneurship melalui kokedama lebih menekankan pada pemanfaatan limbah hingga menjadi produk yang bernilai jual. Sabut kelapa merupakan salah satu limbah yang kurang termanfaatankan. Alasan lain memilih sabut kelapa bukan hanya kuantitas yang melimpah tetapi juga karena ramah lingkungan (Bondra, 2018).

Bioentrepreneurship diaplikasikan secara aktif dengan melibatkan semua stakeholder (pemangku kepentingan), sehingga ada sinergi antara anak-anak disabilitas, pengurus panti, masyarakat, untuk mencapai tujuan program. Tujuan program pengabdian masyarakat ini antara lain Melatih pengurus panti dan anak disabilitas untuk mandiri secara ekonomi dengan melalui kokedama. Keberlanjutan program Panti Asuhan Luar Biasa Asih dalam mengembangkan kokedama dan mewujudkan bioentrepreneurship secara mandiri. Terjalin hubungan sinergis antara tim pengabdian, panti asuhan, masyarakat dalam mengembangkan produk kokedama.

\section{METODE}

Tahapan pelaksanaan kegiatan antara lain sosialisasi program secara inklusi dan pelatihan pembuatan kokedama sesuai dengan jenis ketunaan dan pemasaran produk. Sosialisasi program dengan mengumpulkan pengurus panti dan anak disabilitas yang menjadi sasaran program. Sosialisasi dilakukan dengan menyesuaikan kemampuan disabilitas. Tim juga menggunakan bahasa isyarat untuk mempermudah bagi anak tuna rungu. Materi sosialisasi disampaikan oleh Novanda Eka Saputra dari Program Studi Pendidikan Biologi Universitas PGRI Madiun. Pelatihan dihadiri 11 orang penyandang disabilitas, dan 5 orang pengasuh panti.

Anak Panti yang dipilih adalah mereka dengan tingkat ketunaan ringan. Menurut Mayasari (2019) "Seorang penyandang disabilitas, memiliki kemampuan yang berbeda dalam melakukan kegiatan yang umum dilakukan oleh non disabilitas".

Peserta dan tim pelatih dibagi menjadi 4 kelompok sesuai dengan jenis ketunaan yaitu kelompok A untuk tuna netra, kelompok B untuk tuna rungu, kelompok $\mathrm{C} 1$ dan $\mathrm{C} 2$ untuk tuna grahita ringan. Pelatihan bertempat di halaman Panti Asuhan Luar Biasa Asih. Peserta pelatihan juga diberi modul kokedama sesuai jenis ketunaan untuk mempermudah penyampaian informasi.

Pemasaran dilaksanakan di Car Free Day Jl. Pahlawan Kota Madiun. Pemasaran melibatkan kepala panti asuhan, pengasuh panti asuhan anak panti dan tim pengabdian masyarakat. Tim pengabdian masyarakat bersifat mendampingi. Pemasaran secara online juga dilakukan. Pemasaran online melalui media sosial instagram dan whatsapp. 


\section{HASIL DAN PEMBAHASAN}

Sosialisasi dan pelatihan pembuatan kokedama telah dilaksanakan pada tanggal 19 Mei 2019 di Halaman Panti Asuhan Anak Luar Biasa Asih Madiun, Jl. Raya Dungus No. 309 Kabupaten Madiun. Pelatihan menggunakan pendekatan inklusi. Menurut Skjorten (2003) Pendekatan inklusi bertujuan untuk adanya dari perubahan-perubahan sebagai pengakuan dan penghargaan akan adanya keragaman. Hal ini tersebut menghasilkan usaha untuk "membawa kembali" anak disabilitas ke dalam masyarakat yang terampil.

Langkah-langkah

pembuatan kokedama adalah (1) Menampurkan tanah dengan pupuk kompos dengan perbandingan $1: 1$. (2) mengaduk campuran kedua bahan hingga menyatu dengan air secukupnya. (3) Membungkus akar tanaman yang sudah dibersihkan sebelumnya dengan campuran media pada langkah 1 sampai berbentuk bola menyelubungi akar tanaman. (4) Setelah berbentuk bola, membungkus tanaman dengan lembaran sabut kelapa. (5) mengikat tali di sekeliling bola tanah mengikuti bentuk bulatannya. Menambahkan tali untuk dibuat dengan model tanaman gantung. menyirami dengan air sekitar 3-5 hari sekali tergantung dari jenis tanaman dan kelembaban.

Keunggulan produk kokedama antara lain memanfaatkan limbah sabut kelapa menjadi barang bermanfaat dan memiliki daya jual, mayoritas tanaman kokedama adalah tanaman dengan intensitas penyiram rendah, subtitusi pot plastik yang merupakan bahan non-biodegradable dengan limbah sabut kelapa yang biodegradable, kokedama dapat diletakan di dalam atau digantung di luar ruangan, dan kokedama sebagai salah satu

Pemasaran produk dilaksanakan di Car Free Day Jl. Pahlawan Koata Madiun. Alasan pemilihan CFD karena kokedama merupakan produk modern yang cocok untuk masyarakat kota dengan kondisi lahan sempit. Mayoritas pembeli di CFD Madiun adalah warga Kota Madiun, yang memiliki lahan sempit dan banyak memiliki tanaman hias Pemasaran produk juga dilakukan pada media sosial melalui aplikasi whatsapp dan instagram. solusi kekurangan lahan hijau di rumah. Menurut Ruwana (2015) Bahan serat serabut kelapa memiliki beberapa kelebihan elastisitas, kuat, tahan pada penguraian mikroba, biodegradable, tahan terhadap salinitas dan banyak keterseadian di alam.

Keunggulan- keunggulan produk tersebut sudah sesuai dengan kriteria sasaran mitra di Panti Asuhan Luar Biasa Asih dengan latar belakang anak disabilitas dan mempunyai lahan sempit. Kelemahan produk pada produksi kokedama selanjutnya antara lain tanaman yang dapat digunakan sebatas tanaman hias, untuk tanaman produktif kurang cocok diaplikasikan.



Gambar 1. Pembukaan Kegiatan PKM

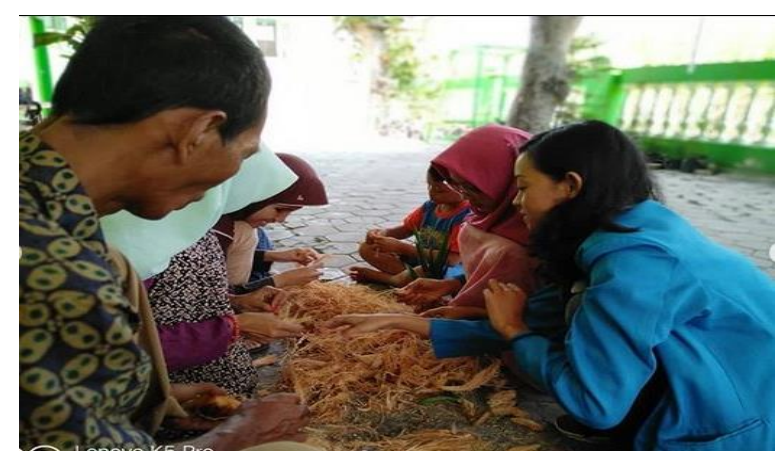

Gambar 2 : Sosialisasi dan Pelatihan Kokedama



Gambar 3. Pemasaran di CFD Madiun 


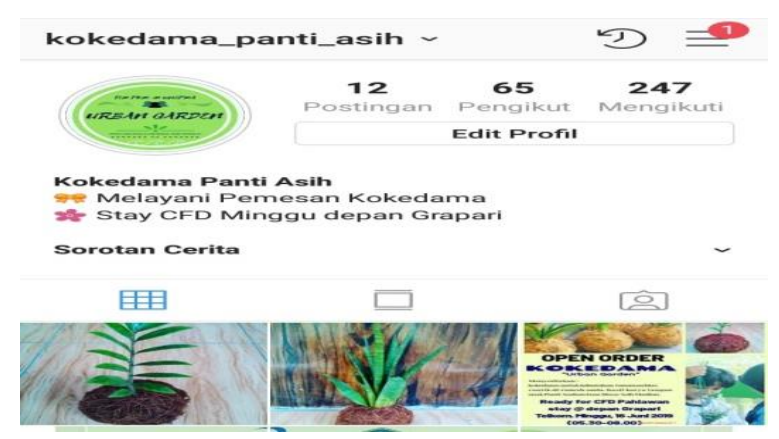

Gambar 3: Pemasaran di Media Sosial

\section{SIMPULAN DAN SARAN}

Kesimpulan dari Pengabdian Masyarakat ini antara lain pengurus panti dan anak disabilitas mendapatkan peningkatan pendapatan kokedama. Terwujudnya bioentrepreneurship secara mandiri Terjalin hubungan sinergis antara tim pengabdian, panti asuhan, masyarakat dalam mengembangkan produk kokedama. Saran untuk keberlanjutan program agar penambahan platform e-commerce agar jaringan pemasaran lebih luas dan Pembuatan kokedama dari lumut sebagai penutup untuk menambah variasi produk.

\section{DAFTAR RUJUKAN}

Aji, A. L. D., \& Haryani, T. N. (2017). Diversitas dalam Dunia Kerja: Peluang dan Tantangan bagi Disabilitas. Spirit Publik, 12(2), 83-93.

Bondra, M., Setiawan, A. P., \& Nilasari, P. F. (2018). Penelitian Serabut Kelapa Sebagai Material Lantai Ecofriendly dan Biodegradable. Intra, 6(2), 431-436.

Garneti, A. E. (2017). Analisis Strategi Pemasaran Dalam Upaya Peningkatan Volume Penjualan Tanaman Hias Boneka Lumut Dengan Media Tanam Kokedama Pada Umkm Planter Craft Bandung (Doctoral dissertation, Universitas Brawijaya).
Hamidi, J. (2016). Perlindungan Hukum terhadap Disabilitas dalam Memenuhi Hak Mendapatkan Pendidikan dan Pekerjaan. Jurnal Fakultas Hukum UII, 23(4), 652-671.

Thomson, D. (2016). Kokedama - The Japanese String Gardens. http://www.medium.com (diakses pada 11 Juni 2019)

Megahati, R. R. P., Maizeli, A., \& Fitriani, V. (2019). Pemberdayaan Anak-Anak Panti Asuhan PGAI dan Darul Ma'rif di Kota Padang Menjadi Bioentrepreneur. Jurnal Penelitian dan Pengabdian Kepada Masyarakat UNSIQ, 6(2), 50-53.

Prakosa, P. W. (2005). Dimensi Sosial Disabilitas Mental di Komunitas Semin, Yogyakarta. Sebuah Pendekatan Representasi Sosial. Jurnal Psikologi, 32(2), 61-73.

Mayasari, U., Dwiyanti, N., Nindy, D. T., \& Prihatiningrum, (2019). B. T-Bandable: Toothbrush Band untuk Anak Berkebutuhan Khusus (Difabel)(TBandable: Toothbrush Band for Special Needs Children (Difabel))

Ruwana, I., \& Hutabarat, J. (2015). Perancangan Rompi Anti Cidera Berbahan Coir Fiber (Serabut Kelapa) Yang Ergonomis. PROCEDING NASIONAL TEKNOLOGI (SENATEK), 673-680 